\title{
Selected Quality Attributes of Wheat Flour Added with Overozonized Wheat Flour
}

\author{
Wei Zhang $\mathbb{D}^{1,2}$, Xianli Luo, ${ }^{1}$ Liuyan Li, ${ }^{1}$ Zaixi Shu, ${ }^{1,2}$ Pingping Wang, ${ }^{1,2}$ and Xuefeng Zeng ${ }^{3}$ \\ ${ }^{1}$ College of Food Science and Engineering, Wuhan Polytechnic University, Wuhan 430023, China \\ ${ }^{2}$ Key Laboratory for Deep Processing of Major Grain and Oil (Wuhan Polytechnic University), Ministry of Education, \\ Wuhan 430023, China \\ ${ }^{3}$ School of Liquor and Food Engineering, Guizhou University, Guiyang 550000, China \\ Correspondence should be addressed to Wei Zhang; zhangwei_food@163.com
}

Received 7 February 2021; Revised 28 May 2021; Accepted 5 June 2021; Published 12 June 2021

Academic Editor: Yan Zhang

Copyright (C) 2021 Wei Zhang et al. This is an open access article distributed under the Creative Commons Attribution License, which permits unrestricted use, distribution, and reproduction in any medium, provided the original work is properly cited.

\begin{abstract}
Overozonized wheat flour was added to unozonized wheat flour at three different ratios (M1:1:1;M2:1:2; and M3:1:3), and the mixed flour was evaluated for quality properties, including $\mathrm{pH}$, protein component, dough property, pasting property, and steamed bread quality. The $\mathrm{pH}$ of the mixed flour gradually increased as the addition content of overozonized flour decreased. The three mixed flour had higher insoluble polymeric protein (IPP) content than unozonized flour. Compared with overozonized flour, M1 and M2 flour did not show a significant difference in IPP content, but M3 flour exhibited a decreased IPP content. Three mixed flour had higher dough development time and dough stability time than both unozonized and overozonized flour, and there was no significant difference among three mixed flour in these two dough parameters. Peak, trough, and final viscosities of the three mixed flour were between those of unozonized and overozonized flour. Steamed bread of three mixed flour had larger specific volume and better texture than that of overozonized flour, with steamed bread of M3 flour showing the best attributes. Among the three mixed flour, M1 flour was the closest to overozonized flour in volatile compounds of steamed bread. These results suggested overozonized flour can be mixed with unozonized flour to decrease the deterioration of overozonization on the dough and food-making properties of wheat flour, but the mixing ratio should be taken into consideration to obtain a better quality.
\end{abstract}

\section{Introduction}

Wheat is a staple cereal for nearly $35 \%$ of the world's population. As a dietary source of carbohydrates and proteins, wheat plays an important role in meeting energy and nutrient requirements of humans. Ozone $\left(\mathrm{O}_{3}\right)$ is the triatomic oxygen formed by addition of a free radical of oxygen to molecular oxygen. It is a potent oxidant that is generally recognized as safe (GRAS) for intended use in food since 1997 [1]. Ozone is not stable and can rapidly decompose into oxygen during usage [2]. Due to unique attributes, ozone attracts considerable research interest for applications in wheat grains and flour.

During the storage and processing process of wheat grains and flour, ozone is a good candidate for fumigation gas, which can kill insects and inhibit the growth of microbes [3-6]. Ozone can react with mycotoxins (e.g., deoxynivalenol and aflatoxin) and reduce their toxicities by damaging their molecular structures [7-9]. Ozone is also effective in degrading residual pesticides that are used during the growth period, such as bifenthrin, deltamethrin, fenitrothion, and pirimiphos-methyl $[10,11]$.

As application research of ozone in wheat expands, its impact on properties of wheat flour has been gaining evergrowing attention. Li et al. [12] found that the development time and stability time of noodle dough was significantly increased as flour was treated with ozone treatment. Li et al. [13] observed the rise of dough development time and stability time as moistened wheat kernel were treated with ozone gas. However, deteriorated dough properties were 
reported to overozonized wheat flour. Sandhu et al. [14] reported that dough stabilities of wheat flour exhibited a trend of increase at the initial stage of ozone treatment, followed by a decrease as treatment prolonged.

The food-making property of ozonized wheat flour varies with the ozone treatment condition. Li et al. [12] reported that moderate ozonization of wheat flour could improve the texture of the noodle products. However, Mei et al. [15] reported that overozonization of wheat flour had a negative effect on quality scores, volume, and structure of the steamed bread products. Mixing with unozonized wheat flour can be a simple strategy to utilize the overozonized wheat flour. However, to date, there have been few systematic studies reported on the quality attributes of the blends of overozonized and unozonized wheat flour. In this study, overozonized wheat flour was added to the unozonized at different ratios $(1: 1,1: 2$, and $1: 3)$, and the mixed flour was compared in dough properties, protein composition, $\mathrm{pH}$, pasting properties, and qualities of the steamed bread products. This research can provide a reference for the proper application of ozone treatment in wheat industry.

\section{Materials and Methods}

2.1. Materials. Wheat grains (variety Xinong 797), harvested in 2019, were kindly supplied by a farmer in Xiangyang (China). Wheat grains were milled to flour using a Buhler MLU-202 mill (Buhler Group, Uzwil, Switzerland) with an extraction rate of around 70\%. Acetonitrile, 1-propanol, and trifluoroacetic acid, chromatographic grade, were supplied by Sinopharm Chemical Reagent Co., Ltd. (Shanghai, China). Nitrogen gas with a purity of $99.999 \%$ was supplied by the Wuhan Minghui Gas Science and Technology Co., Ltd. (Wuhan, China). Other chemicals were of analytical grade unless otherwise stated.

\subsection{Preparation of Overozonized Wheat Flour and Its Mixing} with Unozonized Flour. Ozone gas was generated by using an ozone generator (HW-ET-20, Guangzhou Huanwei Environment Protection Science and Technology Co., Ltd., Jinan, China). Wheat flour ( $300 \mathrm{~g})$ was treated with ozone gas at an air flow rate of $2.5 \mathrm{~L} / \mathrm{min}$, corresponding to an ozone flow rate of $3.8 \mathrm{~g} / \mathrm{h}$. Overozonized flour was obtained after $15 \mathrm{~min}$ of ozone treatment [15]. Overozonized flour was stored in a polyethylene bag in a refrigerator. After one week of storage, overozonized flour was mixed with unozonized flour in a glass bottle, which was vigorously shaken by hand to ensure uniformity. The mixed flour with overozonized flour/unozonized flour ratios (dry weight) of $1: 1,1: 2$, and $1: 3$ was coded as M1, M2, and M3, respectively. The unozonized flour and overozonized flour were coded as UOF and OOF, respectively. All these flour were stored in polyethylene bags in a refrigerator until use.

2.3. Determination of the $\mathrm{pH}$ of Wheat Flour. The $\mathrm{pH}$ of wheat flour was determined according to AACC method 02-52.
2.4. Protein Composition Analysis of Wheat Flour by SizeExclusion High-Performance Liquid Chromatography (SEHPLC). Protein composition of wheat flour was analyzed by the SE-HPLC method described by Schober et al. [16] with a slight modification. In brief, wheat flour was extracted with aqueous 50\% 1-propanol, and the unextractable fraction was lyophilized. The nitrogen content of the dried unextractable fraction was determined by the combustion method to calculate the insoluble polymeric protein (IPP) content using a nitrogen-to-protein conversion factor of 5.70. Extractable fraction was analyzed with SE-HPLC to obtain the percentages of soluble polymeric protein (SPP), gliadin (Gli), and albumin and globulin (Alb/Glob). SE-HPLC was performed using a Waters e2695 HPLC system (Milford, MA, USA) and a Biosep SEC-4000 column (Phenomenex, Torrance, CA, USA). The injection volume was $20 \mu \mathrm{L}$, and UV-detection was conducted at $210 \mathrm{~nm}$. The column temperature was maintained at $40^{\circ} \mathrm{C}$, and the mobile phase was $50 \%$ acetonitrile and $0.1 \%(\mathrm{w} / \mathrm{v})$ trifluoroacetic acid at a flow rate of $0.5 \mathrm{~mL} / \mathrm{min}$.

2.5. Dough Property Analysis of Wheat Flour. The dough property of wheat flour was investigated by Mixolab (Chopin, Tripette \& Renaud, Paris, France) according to AACC method 54-60.01. The Mixolab device was used to determine water absorption (WA), dough development time (DDT), and dough stability time (DST).

2.6. Pasting Property Analysis of Wheat Flour. The pasting profiles of wheat flour were determined using a Rapid Visco Analyser (RVA, Newport Scientific Pvt. Ltd., Warriewood, Australia). Flour dispersion $(12 \% \mathrm{w} / \mathrm{w})$ was equilibrated at $50^{\circ} \mathrm{C}$ for $1 \mathrm{~min}$ and then increased to $95^{\circ} \mathrm{C}$ at a rate of $12^{\circ} \mathrm{C} /$ min, held for $2.5 \mathrm{~min}$, cooled to $50^{\circ} \mathrm{C}$ at a rate of $12{ }^{\circ} \mathrm{C} / \mathrm{min}$, and held for $2 \mathrm{~min}$. The paddle speed was set at $960 \mathrm{rpm}$ for the first $10 \mathrm{~s}$ and then was reduced to $160 \mathrm{rpm}$ throughout the rest of the experiment.

2.7. Steamed-Bread-Making Process. The steamed bread was made according to the work of Sandhu et al. [14]. The dough was fermented at $30^{\circ} \mathrm{C}$ and $85 \%$ relative humidity in a GVAS fully automatic proofing cabinet (MIWE Michael Wenz $\mathrm{GmbH}$, Arnstein, Germany). After fermentation, the dough was sheeted 20 times on a dough sheeter (MP800, Yechang Food machinery Co., Ltd., Shanghai, China) and split into $100 \mathrm{~g}$ portions. The dough chunks were formed into rounded shapes by hand and fermented at $30^{\circ} \mathrm{C}$ and $85 \%$ relative humidity for $35 \mathrm{~min}$. The proofed doughs were steamed for $25 \mathrm{~min}$ in a pot using a steam tray and boiling water. After cooling at room temperature for $1 \mathrm{~h}$, the quality of the steamed bread was evaluated.

2.8. Specific Volume, Crumb Structure, and Texture Analysis of the Steamed Bread. The specific volume of the steamed bread was measured using a BVM-L370 volume measurer (Perten Instruments, Hägersten, Sweden). The crumb structure of the steamed bread was analyzed using the C-Cell 


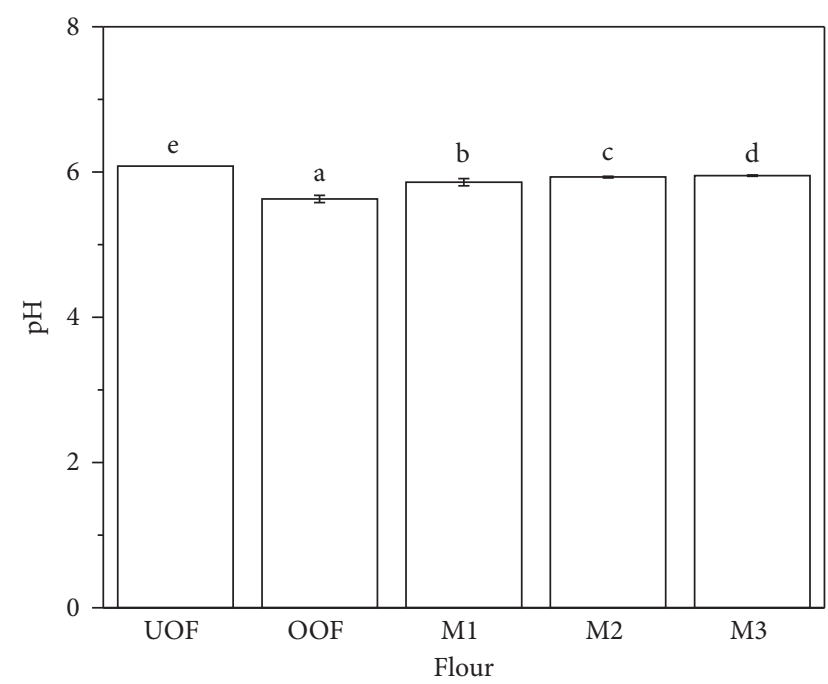

FIGURE 1: pH values of wheat flour added with different ratios of overozonized wheat flour. Means with the same letter were not significantly different $(\alpha=0.05)$.

Imaging System (Perten Instruments, Hägersten, Sweden). The texture of the steamed bread was tested using the TAXT2i texture analyzer (Stable Micro Systems, Surrey, UK) with its Pasta Firmness/Stickiness Rig probe (P35). The steamed bread was cut into pieces of $15 \mathrm{~mm}$ thickness. The texture analyzer was set as follows: trigger type, auto-5 g; pretest speed, $3 \mathrm{~mm} / \mathrm{s}$; posttest speed, $1 \mathrm{~mm} / \mathrm{s}$; test speed, $1 \mathrm{~mm} / \mathrm{s}$; compression ratio, $60 \%$; interval between consecutive compressions, $3 \mathrm{~s}$; and compression time, 2 times.

\subsection{Analysis of Volatile Compounds by Gas Chromatography-} Ion Mobility Spectrometry (GC-IMS). Volatile compounds of the steamed bread were analyzed using a FlavourSpec ${ }^{\circledR}$ GCIMS instrument (Gesellschaft für Analytische Sensorsysteme $\mathrm{mbH}$, Dortmund, Germany). Gas chromatography (GC) was performed with a $30 \mathrm{~m} \mathrm{OV}-5$ column to separate the volatile compounds. Nitrogen gas of $99.999 \%$ purity was used as the carrier gas. The elution gas was maintained at $5 \mathrm{~mL} / \mathrm{min}$ for $2 \mathrm{~min}$, increased to $100 \mathrm{~mL} / \mathrm{min}$ in $10 \mathrm{~min}$, then increased to $150 \mathrm{~mL} / \mathrm{min}$ in $4 \mathrm{~min}$, and maintained at this temperature for $1 \mathrm{~min}$. The analytes were eluted and separated at $45^{\circ} \mathrm{C}$, and then ionized in an IMS ionization chamber. Nitrogen gas at a flow rate of $150 \mathrm{~mL} / \mathrm{min}$ was used as the drift gas for IMS, and the drift tube temperature was set at $45^{\circ} \mathrm{C}$. IMS was performed at $45^{\circ} \mathrm{C}$.

Data from GC-IMS were analyzed using LAV software, GC-IMS Library Search software, Gallery plot, and dynamic PCA plug-ins. The volatile compounds were identified with GC-IMS Library search by using the NIST database and the IMS database. LAV software was used to perform quantitative analysis after establishing standard curves. The Gallery plot plug-in was used to perform fingerprint comparison of the volatile compounds of samples. The dynamic PCA plugin was used to perform principal component analysis.

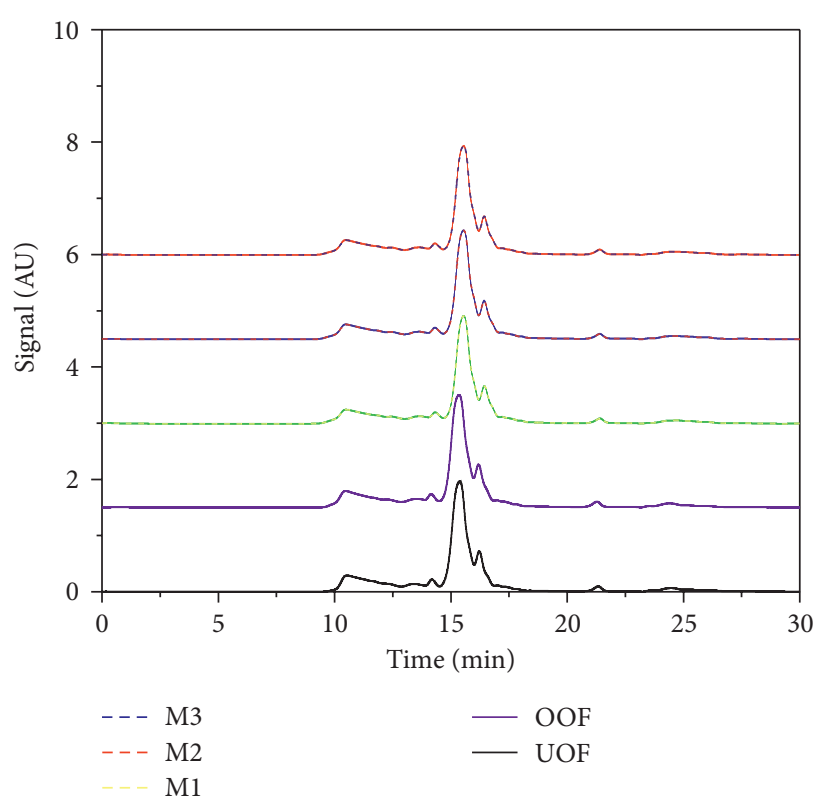

FIgURE 2: SE-HPLC chromatograms for extractable protein of wheat flour added with different ratios of overozonized wheat flour.

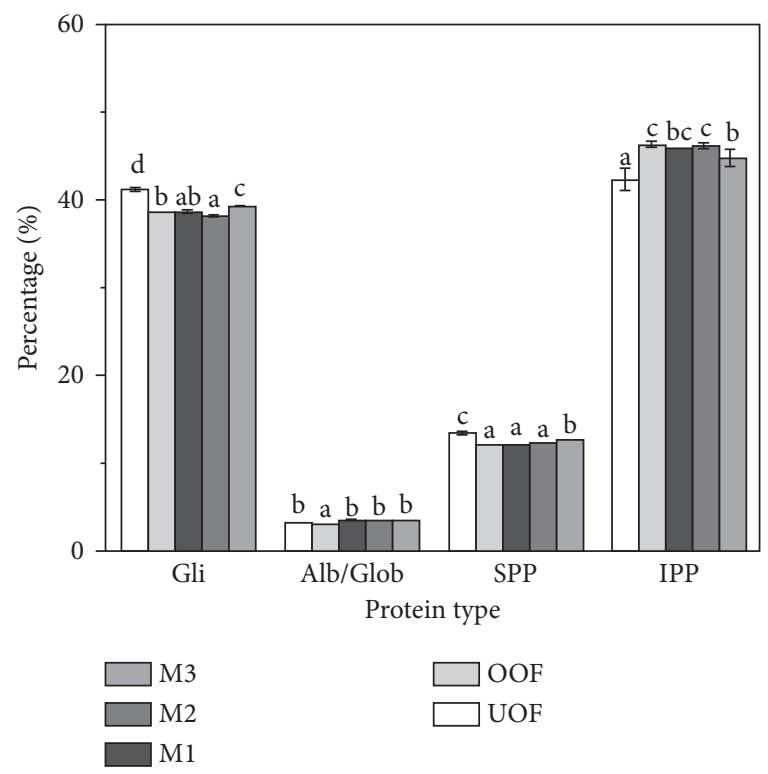

Figure 3: Percentages of protein fractions of wheat flour added with different ratios of overozonized wheat flour. For a specific protein fraction, means with the same letter were not significantly different $(\alpha=0.05)$.

2.10. Statistical Analysis. Data are averages of duplicate observations and expressed as means \pm standard deviations. An analysis of variance with a significance level of 5\% was conducted, and Duncan's test was applied to determine differences between means using the commercial statistical package (SPSS Inc., Chicago, IL, USA). 


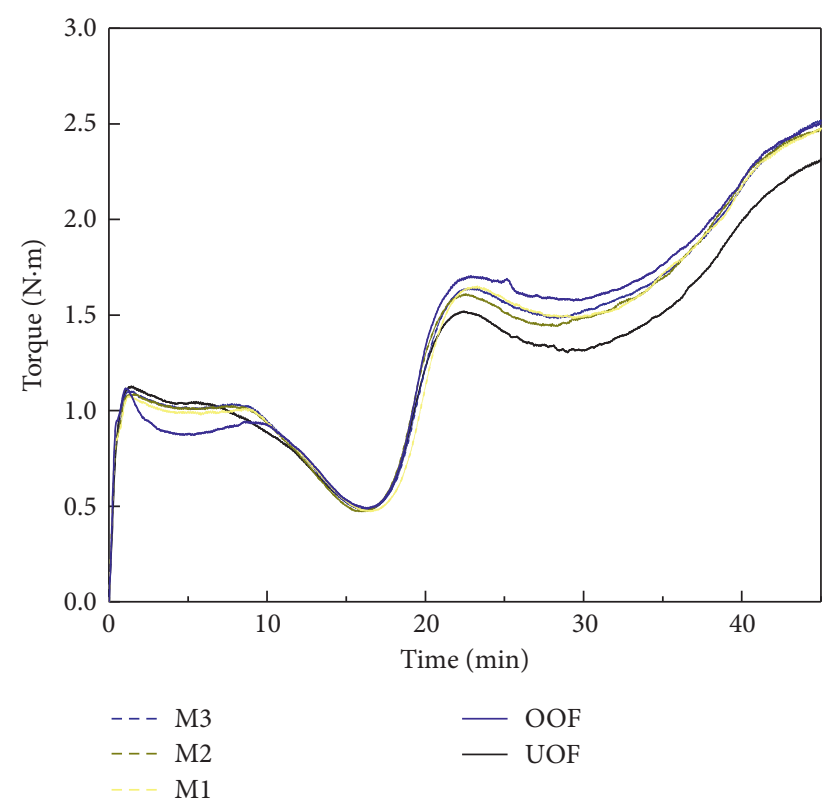

FIGURE 4: Mixolab curves of wheat flour added with different ratios of overozonized wheat flour.

\section{Results and Discussion}

3.1. $p H$. The acidity of wheat flour directly affects the property of dough [17]. $\mathrm{pH}$ values of wheat flour added with different ratios of overozonized wheat flour are shown in Figure 1 . The $\mathrm{pH}$ of overozonized wheat flour was significantly lower than that of unozonized flour. This result might be due to the structure change of starch and lipids during ozone treatment. Under ozone treatment, hydroxyl groups of starch can be oxidized to carbonyl and carboxyl groups [18]. Ozone can react with unsaturated lipids through Criegee reaction, giving rise to acidic products $[19,20] . \mathrm{pH}$ values of the three mixed flour were between those of the overozonized flour and unozonized flour. With the addition ratio of overozonized flour decreased, $\mathrm{pH}$ of the mixed flour gradually got close to the unozonized flour and away from overozonized flour.

3.2. Protein Composition. Wheat protein comprises of four major types: glutenin, gliadin, albumin, and globulin. The insoluble polymeric protein (IPP) of glutenin is considered important in determining gluten quality [21]. HPLC chromatograms of extractable protein of wheat flour added with different ratios of overozonized wheat flour are displayed in Figure 2, and protein compositions of wheat flour are shown in Figure 3. As Figure 3 shows, overozonized wheat flour had lower SPP (soluble polymeric protein) content and higher IPP content than unozonized wheat flour. Chittrakorn et al. [22] suggested that ozone treatment of wheat flour could enhance the crosslinking of glutenin from low-molecularweight polymeric protein to high-molecular-weight polymeric protein, leading to the increase of IPP fraction. Three mixed flour had higher IPP contents and lower SPP contents than unozonized flour. Compared to overozonized flour, M2
TABLE 1: The Mixolab parameters of wheat flour added with different ratios of overozonized wheat flour ${ }^{\dagger}$.

\begin{tabular}{lccc}
\hline & WA (\%) & DDT (min) & DST (min) \\
\hline UOF & $66.10 \pm 0.00^{\mathrm{b}}$ & $1.13 \pm 0.02^{\mathrm{b}}$ & $7.61 \pm 0.52^{\mathrm{a}}$ \\
OOF & $71.30 \pm 0.66^{\mathrm{c}}$ & $1.04 \pm 0.03^{\mathrm{a}}$ & $1.74 \pm 0.16^{\mathrm{d}}$ \\
M1 & $66.00 \pm 0.17^{\mathrm{b}}$ & $1.32 \pm 0.06^{\mathrm{c}}$ & $9.48 \pm 0.09^{\mathrm{b}}$ \\
M2 & $65.73 \pm 0.35^{\mathrm{b}}$ & $1.42 \pm 0.17^{\mathrm{c}}$ & $9.26 \pm 0.08^{\mathrm{b}}$ \\
M3 & $64.83 \pm 0.29^{\mathrm{a}}$ & $1.40 \pm 017^{\mathrm{c}}$ & $9.34 \pm 0.19^{\mathrm{b}}$ \\
\hline
\end{tabular}

${ }^{\dagger}$ Data were expressed as means \pm SD. Means within a column that had the same letter were not significantly different $(\alpha=0.05)$. WA $=$ water absorption; DDT $=$ dough development time; $\mathrm{DST}=$ dough stability time.

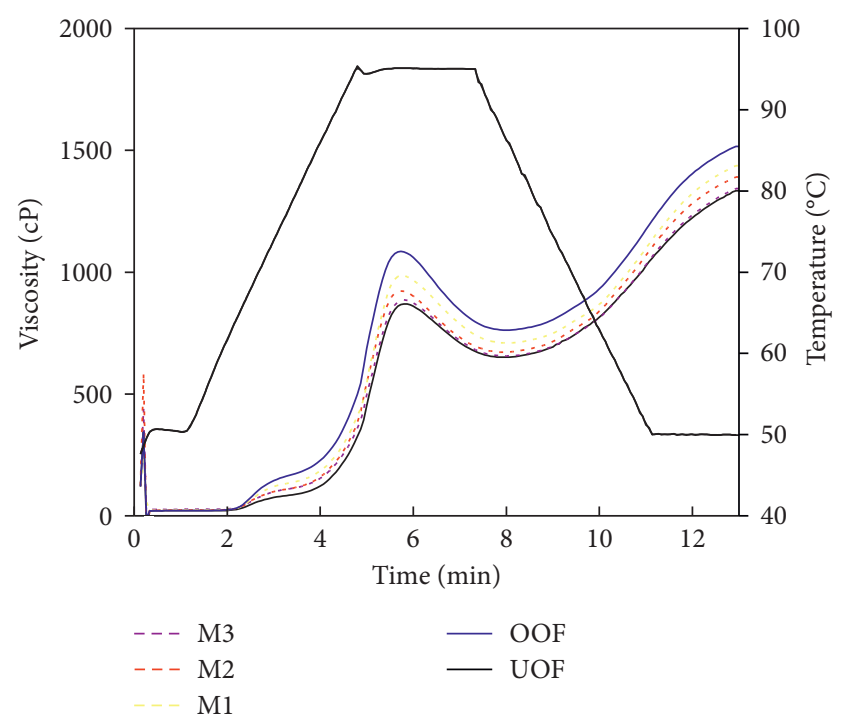

Figure 5: RVA curves of wheat flour added with different ratios of overozonized wheat flour.

and M1 flour did not show a significant difference in IPP content, but M3 flour exhibited a significantly decreased IPP content. This suggested that adding different amounts of overozonized wheat flour can make a difference in the glutenin structure of the mixed flour and the mixed flour was close to overozonized flour in IPP content at higher addition amounts.

3.3. Dough Property. Mixolab curves and parameters of wheat flour added with different ratios of overozonized wheat flour are shown in Figure 4 and Table 1, respectively. The water absorption (WA) of overozonized flour was significantly higher than that of unozonized flour. This result was consistent with the work of Mei et al. [15]. As compared to unozonized wheat flour, overozonized flour exhibited a significant decrease in dough development time (DDT) and dough stability time (DST), indicating that dough strength was weakened. This result was consistent with the work of Zhuang et al. [23] and Zhang et al. [24]. The ozone-induced decrease of flour in DDT and DST was in contrast with the increased IPP content. This inconsistency can be attributed to the decrease of the $\mathrm{pH}$ value. Increase in acidity of wheat flour would result in stiffer and more fragile dough [25]. The DDT and DST of three mixed 
TABLE 2: The pasting parameters of wheat flour added with different ratios of overozonized wheat flour ${ }^{\dagger}$.

\begin{tabular}{lccccc}
\hline & PV $(\mathrm{cP})$ & TRV $(\mathrm{cP})$ & BDV $(\mathrm{cP})$ & FV $(\mathrm{cP})$ & SBV $(\mathrm{cP})$ \\
\hline UOF & $870.0 \pm 26.9^{\mathrm{a}}$ & $651.0 \pm 12.7^{\mathrm{a}}$ & $219.0 \pm 14.1^{\mathrm{a}}$ & $1334.0 \pm 43.8^{\mathrm{a}}$ & $683.0 \pm 31.1^{\mathrm{a}}$ \\
OOF & $1085.5 \pm 29.0^{\mathrm{d}}$ & $762.0 \pm 19.8^{\mathrm{d}}$ & $323.5 \pm 9.2^{\mathrm{d}}$ & $1516.5 \pm 19.1^{\mathrm{d}}$ & $754.5 \pm 0.7^{\mathrm{c}}$ \\
M1 & $986.0 \pm 11.3^{\mathrm{c}}$ & $709.5 \pm 10.6^{\mathrm{c}}$ & $276.5 \pm 0.7^{\mathrm{c}}$ & $1436.5 \pm 21.9^{\mathrm{bc}}$ & $727.0 \pm 11.3^{\mathrm{b}}$ \\
M2 & $923.5 \pm 23.3^{\mathrm{b}}$ & $671.5 \pm 14.9^{\mathrm{b}}$ & $252.0 \pm 8.5^{\mathrm{b}}$ & $1390.5 \pm 14.9^{\mathrm{b}}$ & $719.0 \pm 17.5^{\mathrm{b}}$ \\
M3 & $985.0 \pm 1.4^{\mathrm{c}}$ & $726.5 \pm 5.0^{\mathrm{c}}$ & $258.5 \pm 3.5^{\mathrm{bc}}$ & $1472.5 \pm 5.0^{\mathrm{c}}$ & $746.0 \pm 10.0^{\mathrm{b}}$ \\
\hline
\end{tabular}

${ }^{\dagger}$ Data were expressed as means \pm SD. Means within a column that had the same letter were not significantly different $(\alpha=0.05)$. PV = peak viscosity; $\mathrm{TRV}=$ trough viscosity; $\mathrm{BDV}=$ breakdown viscosity; FV = final viscosity; $\mathrm{SBV}=$ setback viscosity.

TABLE 3: The specific volumes and texture attributes of steamed bread made from wheat flour added with different ratios of overozonized wheat flour ${ }^{\dagger}$.

\begin{tabular}{lccccc}
\hline & Specific volume $(\mathrm{mL} / \mathrm{g})$ & Hardness & Chewiness & Elasticity & Resilience \\
\hline UOF & $2.74 \pm 0.10^{\mathrm{e}}$ & $1439.2 \pm 31.6^{\mathrm{a}}$ & $1060.8 \pm 16.3^{\mathrm{a}}$ & $0.889 \pm 0.024^{\mathrm{b}}$ & $0.465 \pm 0.008^{\mathrm{c}}$ \\
OOF & $1.78 \pm 0.01^{\mathrm{a}}$ & $4527.4 \pm 39.9^{\mathrm{e}}$ & $2981.9 \pm 290.3^{\mathrm{c}}$ & $0.838 \pm 0.016^{\mathrm{a}}$ & $0.452 \pm 0.020^{\mathrm{bc}}$ \\
M1 & $2.27 \pm 0.01^{\mathrm{c}}$ & $2275.1 \pm 97.2^{\mathrm{c}}$ & $1630.6 \pm 124.7^{\mathrm{b}}$ & $0.898 \pm 0.045^{\mathrm{b}}$ & $0.433 \pm 0.013^{\mathrm{b}}$ \\
M2 & $2.11 \pm 0.10^{\mathrm{b}}$ & $2515.1 \pm 11.6^{\mathrm{d}}$ & $1571.1 \pm 12.7^{\mathrm{b}}$ & $0.833 \pm 0.020^{\mathrm{a}}$ & $0.375 \pm 0.006^{\mathrm{a}}$ \\
M3 & $2.52 \pm 0.01^{\mathrm{d}}$ & $2152.3 \pm 98.8^{\mathrm{b}}$ & $1579.7 \pm 88.3^{\mathrm{b}}$ & $0.898 \pm 0.011^{\mathrm{b}}$ & $0.456 \pm 0.005^{\mathrm{c}}$ \\
\hline
\end{tabular}

${ }^{\dagger}$ Data were expressed as means \pm SD. Means within a column that had the same letter were not significantly different $(\alpha=0.05)$.

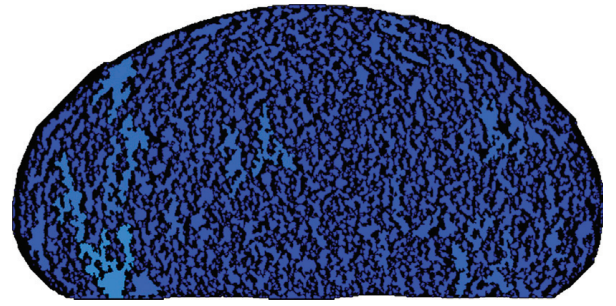

UOF

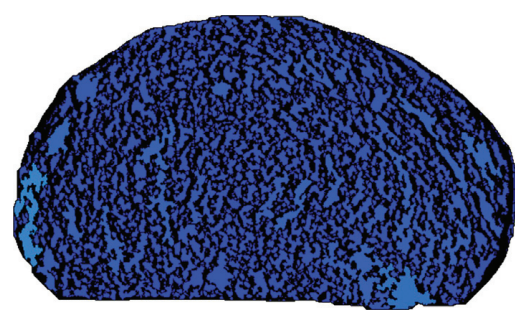

M1

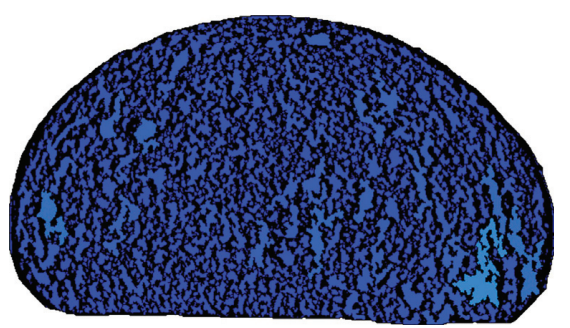

M3

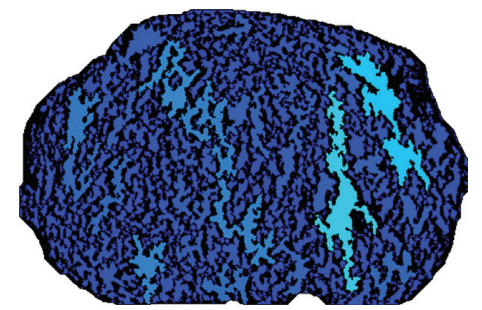

OOF

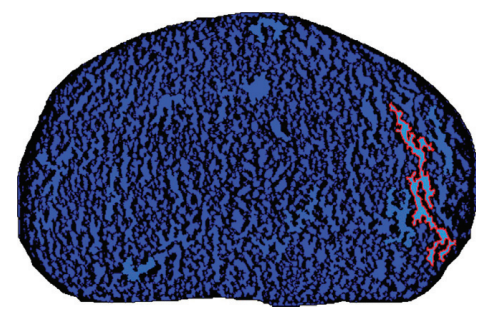

M2

FIgURE 6: C-Cell images of steamed bread made from wheat flour added with different ratios of overozonized wheat flour.

flour were higher than those of unozonized and overozonized flour. This suggested the mixed flour had stronger dough strength than the two individual constituents. The mixed flour had greater IPP content than unozonized flour. Compared with overozonized flour, the mixed flour had a significant increase in the $\mathrm{pH}$ value. These two factors contributed to a superior dough structure of mixed flour relative to the two-constituent flour. There was no significant difference among the three mixed flour in DDT and DST.

3.4. Pasting Property. Pasting curves of wheat flour added with different ratios of overozonized wheat flour are 
TABLE 4: The volatile compounds of steamed bread made from wheat flour ${ }^{\dagger}$.

\begin{tabular}{|c|c|c|c|c|}
\hline Volatile compounds & CAS\# & RI & Rt (s) & Dt (ms) \\
\hline Isopropyl acetate & C108214 & 102.1 & 658.6 & 35.836 \\
\hline Triethylamine & C121448 & 101.2 & 666.3 & 37.846 \\
\hline $\begin{array}{l}\text { 1-Methoxy-2-methyl- } \\
\text { propane }\end{array}$ & C625445 & 88.1 & 574.5 & 19.178 \\
\hline 2-Butanone & C78933 & 72.1 & 585.2 & 21.093 \\
\hline Ethyl & C141786 & 88.1 & 573.5 & 18.986 \\
\hline 3-Methylpentane & C96140 & 86.2 & 583.7 & 20.805 \\
\hline 2-Pentanone & $\mathrm{C} 107879$ & 86.1 & 694.2 & 46.613 \\
\hline Isop & C123513 & 88.1 & 755.2 & 78.756 \\
\hline $2,3-\mathrm{Pe}$ & C600146 & 100.1 & 685.6 & 43.609 \\
\hline Dimethoxyethane & C110714 & 90.1 & 648.3 & 33.347 \\
\hline Acetic acid & C64197 & 60.1 & 617.9 & 27.009 \\
\hline 1-Pr & C71 & 60.1 & & 16.118 \\
\hline Buta & $\mathrm{C} 10$ & 88.1 & 774.3 & 93.979 \\
\hline Ethy & $\mathrm{C} 10$ & 102.1 & & 53.199 \\
\hline $2-\mathrm{Fo}$ & $\mathrm{C} 9$ & 86.1 & & 35.772 \\
\hline & 03 & 98.1 & & 93.462 \\
\hline & $\mathrm{C} 15$ & 84.1 & 739.1 & 67.98 \\
\hline Isob & C7 & 72.1 & 567 & 17.836 \\
\hline Benz & $\mathrm{C} 10$ & 106.1 & 978.4 & 288.66 \\
\hline & & 102.2 & 979 & 289.026 \\
\hline & $\mathrm{C} 33$ & 128.2 & 976.8 & 287.565 \\
\hline $2-\mathrm{H}$ & 30 & 114.2 & 879.7 & 206.494 \\
\hline $2,3-$ & $\mathrm{C} 51$ & 90.1 & 806.8 & 125.868 \\
\hline & & 88.1 & & 109.747 \\
\hline & 28 & 72.1 & & 28.108 \\
\hline Iso & & 74.1 & 617.1 & 26.874 \\
\hline But & 6 & 88.1 & 807.3 & 126.445 \\
\hline & & & & \\
\hline & 70 & 84.1 & & 155 \\
\hline Phes & 8 & 122.2 & 1110.8 & 377.895 \\
\hline & & 104.1 & & 217.033 \\
\hline & & & & \\
\hline & & 74.1 & 3 & 565 \\
\hline & & 74.1 & & 34.912 \\
\hline $3-\mathrm{N}$ & & 86.1 & & 27.113 \\
\hline & & 74.1 & & \\
\hline $\operatorname{Prc}$ & 4 & 74.1 & 9 & 43.711 \\
\hline & & 98.1 & 878.7 & 205.339 \\
\hline Dieth & & 102.1 & & 217.754 \\
\hline $3-\mathrm{Me}$ & 12 & 102.1 & & 162.577 \\
\hline $1-\mathrm{He}_{1}$ & 6 & 116.2 & 978.6 & 288.813 \\
\hline 1-Octe & C3391864 & 128.2 & 977.5 & 288.026 \\
\hline Pentar & C109524 & 102.1 & 917.3 & 242.387 \\
\hline trans & C4313035 & 110.2 & 1018.4 & 315.673 \\
\hline 1-Octe & C4312996 & 126.2 & 975 & 286.34 \\
\hline 3-Octanone & C106683 & 128.2 & 977.8 & 288.271 \\
\hline & C2445763 & 158.2 & 1108.8 & 376.556 \\
\hline $3-\mathrm{N}$ & 431 & 116.2 & 935.1 & 257.157 \\
\hline 2-Phenylet & & 120.1 & 1045.8 & 334.114 \\
\hline Acetol & C116096 & 74.1 & 655.2 & 34.987 \\
\hline 3-Meth & $\mathrm{C} 123513$ & 88.1 & 734.4 & 65.169 \\
\hline 2-But & C78933 & 72.1 & 615.5 & 26.557 \\
\hline n-Pentyl acetate & C628637 & 130.2 & 902.3 & 228.949 \\
\hline 3-Furanmethanol & C4412913 & 98.1 & 977.8 & 288.247 \\
\hline Butanoic acid & C107926 & 88.1 & 790.1 & 108.79 \\
\hline
\end{tabular}

${ }^{\dagger} \mathrm{RI}$ : retention index; Rt: retention time; Dt: drift time. displayed in Figure 5, and pasting parameters are shown in Table 2. As compared to unozonized flour, overozonized flour exhibited an increase in pasting viscosity. Ozoneinduced pasting property change of wheat flour was mainly related to the denaturation of alpha-amylase and oxidation of starch. Ozone treatment could inactivate the alpha-amylase of wheat flour, resulting in the decrease of starch depolymerization in the pasting process [23]. Ozonation could partly oxidize starch molecules, and the negative charges of resultant carboxyl groups increased the swelling of starch granules during heating $[26,27]$. The three mixed flour exhibited peak viscosity (PV), trough viscosity (TRV), and final viscosity (FV) between those of unozonized flour and ozone-treated flour. There were only slight differences among the three flour in pasting parameters.

3.5. Specific Volume, Inner Structure, and Texture of the Steamed Bread. The specific volume and texture attributes of the steamed bread made from wheat flour added with different ratios of overozonized wheat flour are shown in Table 3, and the inner structure of the steamed bread are shown in Figure 6. As compared with the steamed bread of unozonized flour, the steamed bread of overozonized flour exhibited a decrease in specific volume, uniformity of pores and elasticity, and an increase in harness and chewiness. This was consistent with the work of Mei et al. [15]. The steamed bread of the three mixed flour had higher specific volume and lower hardness and chewiness than that of overozonized flour. The steamed bread of the three mixed flour exhibited similar uniform distribution of pores. These results were consistent with the results of dough property. The dough strengths of mixed flour were greater than those of overozonized wheat flour. The enhancement of dough strength could improve the gas-holding capacity of dough, leading to increased specific volume and pore distribution uniformity of the steamed bread. However, the three mixed flour were still inferior to unozonized flour in specific volume and texture attributes of steamed bread products, and there were slight differences among their steamed bread in these parameters. Among the three mixed flour, the steamed bread of M3 flour exhibited the highest specific volume and lowest hardness.

3.6. Volatile Compounds of the Steamed Bread. The volatile compounds of the steamed bread identified by GC-IMS are shown in Table 4, and volatile compound fingerprints of the steamed bread made from different flour are shown in Figure 7. The steamed bread of overozonized and unozonized flour had a significant difference in volatile compounds. As compared to the steamed bread of unozonized flour, more amounts of off-odor compounds were observed in the steamed bread of overozonized flour, including butanoic acid, 1-octen-3-ol, and 


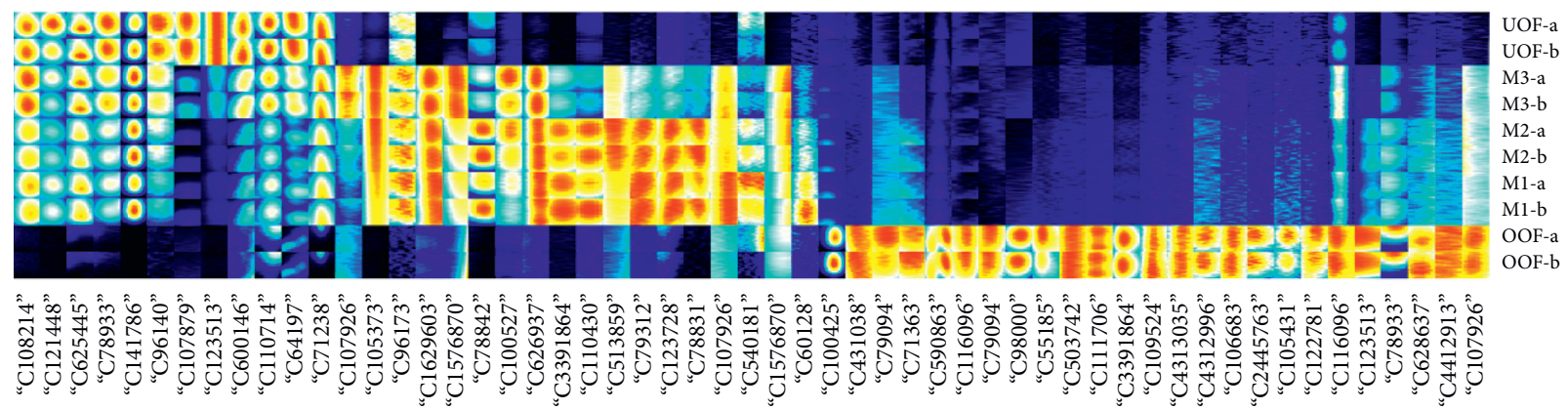

FIGURE 7: Volatile compound fingerprints of steamed bread made from wheat flour added with different ratios of overozonized wheat flour. $\mathrm{a}$ and $\mathrm{b}$ indicate two repetitions of determinations.

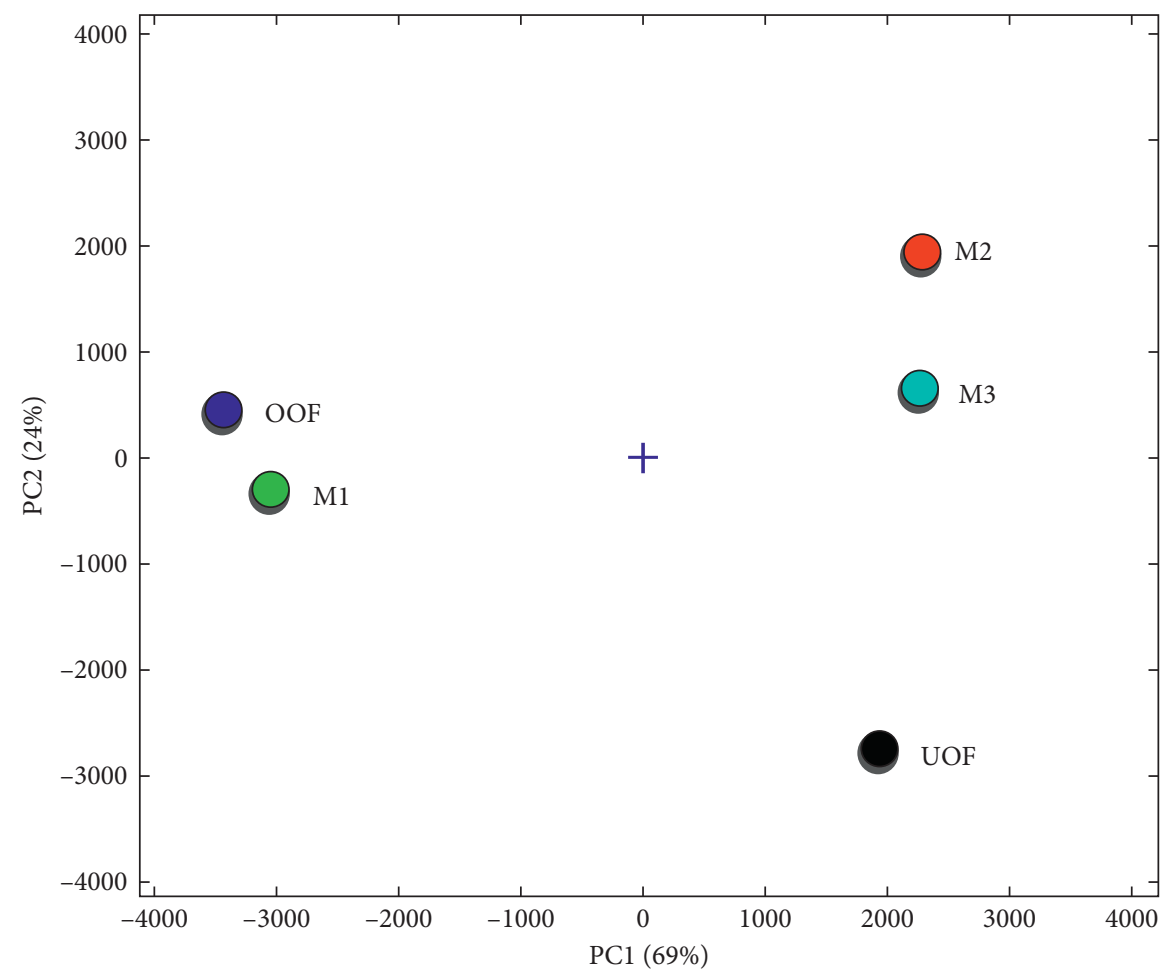

FIGURE 8: PCA plot of volatile compounds of steamed bread made from wheat flour added with different ratios of overozonized wheat flour.

3-methyl-1-butanol [28]. 1-Octen-3-ol was an oxidized product of linoleic acid and was highly related to the rancidity of food fats $[29,30]$. The steamed bread of the three mixed flour exhibited different fingerprints from that of the two-constituent flour. In general, the steamed bread of three mixed flour had lower amounts of off-odor compounds than that of ozone-treated flour.

Principal component analysis (PCA) was performed to analyze the variation in identified volatile compounds in the steamed bread, and the result is shown in Figure 8. The cumulative variance contribution rate of the first part PC1 (69\%) and the second part PC2 (24\%) was 93\%. This result suggested that the two principal components can represent most of the information in the raw data [31]. Different positions were observed for the steamed bread of three mixed flour in the distribution map. The steamed bread of overozonized flour and M1 flour were relatively similar in volatile compounds. The steamed bread of M2 and M3 flour were also similar in volatile compounds.

\section{Conclusions}

The blends of overozonized flour and unozonized flour were better than sole overozonized flour in quality. Compared with overozonized flour, three mixed flour had a decrease in the $\mathrm{pH}$ value and an increase in DDT, DST, and pasting viscosities. Steamed bread of three flour exhibited higher specific volume and lower hardness, chewiness, and off-odor flavor than that of overozonized flour. Three mixed flour were inferior to unozonized flour in specific volume and texture of the steamed bread. Overozonized flour and M1 flour were relatively similar in volatile compounds of steamed bread. M2 and M3 flour were also similar in volatile compounds of steamed bread. These results suggested that 
the mixing of overozonized flour and unozonized flour can alleviate the deterioration of overozonization on the quality of wheat flour. This research can provide a basis for the proper utilization of ozone treatment in wheat industry. Other than steamed bread, the overozonized wheat flour can also be added in the formula of other wheat-based foods, and the effects deserve further research work.

\section{Data Availability}

The data used to support the findings of this study are included within the article.

\section{Conflicts of Interest}

The authors declare that they have no conflicts of interest.

\section{Acknowledgments}

This research was kindly supported by the National Natural Science Foundation of China (grant no. 31801577), the Open Fund of Key Laboratory for Deep Processing of Major Grain and Oil (Wuhan Polytechnic University), Ministry of Education (grant no. 2020JYBQGDKFB09), and the Excellent Science and Technology Innovation Team of Young and Middle-Aged Researchers in Universities of Hubei (grant no. LT201911).

\section{References}

[1] D. M. Graham, "Use of ozone for food processing," Food Technology, vol. 51, pp. 72-75, 1997.

[2] M. V. A. Silva, L. R. A. Faroni, A. H. Sousa, L. H. F. Prates, and A. O. Abreu, "Kinetics of the ozone gas reaction in popcorn kernels," Journal of Stored Products Research, vol. 83, pp. 168-175, 2019.

[3] B. A. Amoah and R. M. Mahroof, "Ozone as a potential fumigant alternative for the management of Sitophilus oryzae (coleoptera: curculionidae) in wheat," Journal of Economic Entomology, vol. 112, no. 4, pp. 1953-1963, 2019.

[4] G. Mishra, A. A. Palle, S. Srivastava, and H. N. Mishra, "Disinfestation of stored wheat grain infested with Rhyzopertha dominica by ozone treatment: process optimization and impact on grain properties," Journal of the Science of Food and Agriculture, vol. 99, no. 11, pp. 5008-5018, 2019.

[5] B. Subramanyam, E. Xinyi, S. Savoldelli, and B. Sehgal, "Efficacy of ozone against Rhyzopertha dominica adults in wheat," Journal of Stored Products Research, vol. 70, pp. 53-59, 2017.

[6] L. Piemontese, M. C. Messia, E. Marconi et al., "Effect of gaseous ozone treatments on DON, microbial contaminants and technological parameters of wheat and semolina," Food Additives \& Contaminants: Part A, vol. 35, no. 4, pp. 761-772, 2018.

[7] L. Wang, Y. Luo, X. Luo et al., "Effect of deoxynivalenol detoxification by ozone treatment in wheat grains," Food Control, vol. 66, pp. 137-144, 2016.

[8] X. Luo, R. Wang, L. Wang, Y. Wang, and Z. Chen, "Structure elucidation and toxicity analyses of the degradation products of aflatoxin b1 by aqueous ozone," Food Control, vol. 31, no. 2, pp. 331-336, 2013.
[9] G. D. Savi, K. C. Piacentini, and V. M. Scussel, "Ozone treatment efficiency in Aspergillus and penicillium growth inhibition and mycotoxin degradation of stored wheat grains (Triticum aestivum L.)," Journal of Food Processing and Preservation, vol. 39, no. 6, pp. 940-948, 2015.

[10] G. D. Savi, K. C. Piacentini, and V. M. Scussel, "Reduction in residues of deltamethrin and fenitrothion on stored wheat grains by ozone gas," Journal of Stored Products Research, vol. 61, pp. 65-69, 2015.

[11] G. D. Savi, K. C. Piacentini, T. Bortolotto, and V. M. Scussel, "Degradation of bifenthrin and pirimiphos-methyl residues in stored wheat grains (Triticum aestivum L.) by ozonation," Food Chemistry, vol. 203, pp. 246-251, 2016.

[12] M. Li, K.-X. Zhu, B.-W. Wang, X.-N. Guo, W. Peng, and H.-M. Zhou, "Evaluation the quality characteristics of wheat flour and shelf-life of fresh noodles as affected by ozone treatment," Food Chemistry, vol. 135, no. 4, pp. 2163-2169, 2012.

[13] M. M. Li, E. Q. Guan, and K. Bian, "Effect of ozone treatment on deoxynivalenol and quality evaluation of ozonised wheat," Food Additives \& Contaminants: Part A, vol. 32, no. 4, pp. 544-553, 2015.

[14] H. P. Sandhu, F. A. Manthey, and S. Simsek, "Quality of bread made from ozonated wheat (Triticum aestivum L.) flour," Journal of the Science of Food and Agriculture, vol. 91, no. 9, pp. 1576-1584, 2011.

[15] J. Mei, G. Liu, X. Huang, and W. Ding, "Effects of ozone treatment on medium hard wheat (Triticum aestivum L.) flour quality and performance in steamed bread making," CyTAJournal of Food, vol. 14, no. 3, pp. 449-456, 2016.

[16] T. J. Schober, S. R. Bean, and M. Kuhn, "Gluten proteins from spelt (Triticum aestivum ssp. spelta) cultivars: a rheological and size-exclusion high-performance liquid chromatography study," Journal of Cereal Science, vol. 44, no. 2, pp. 161-173, 2006.

[17] C. I. Clarke, T. J. Schober, and E. K. Arendt, "Effect of single strain and traditional mixed strain starter cultures on rheological properties of wheat dough and on bread quality," Cereal Chemistry Journal, vol. 79, no. 5, pp. 640-647, 2002.

[18] H. T. Chan, C. P. Leh, R. Bhat, C. Senan, P. A. Williams, and A. A. Karim, "Molecular structure, rheological and thermal characteristics of ozone-oxidized starch," Food Chemistry, vol. 126, no. 3, pp. 1019-1024, 2011.

[19] J. Sadowska, B. Johansson, E. Johannessen, R. Friman, L. Broniarz-Press, and J. B. Rosenholm, "Characterization of ozonated vegetable oils by spectroscopic and chromatographic methods," Chemistry and Physics of Lipids, vol. 151, no. 2, pp. 85-91, 2008.

[20] E. Ugazio, V. Tullio, A. Binello, S. Tagliapietra, and F. Dosio, "Ozonated oils as antimicrobial systems in topical applications, their characterization, current applications, and advances in improved delivery techniques," Molecules, vol. 25, no. 2, p. $334,2020$.

[21] A. L. Girard, S. R. Bean, M. Tilley, S. L. Adrianos, and J. M. Awika, "Interaction mechanisms of condensed tannins (proanthocyanidins) with wheat gluten proteins," Food Chemistry, vol. 245, pp. 1154-1162, 2018.

[22] S. Chittrakorn, D. Earls, and F. MacRitchie, "Ozonation as an alternative to chlorination for soft wheat floursflours," Journal of Cereal Science, vol. 60, no. 1, pp. 217-221, 2014.

[23] K. Zhuang, C. Zhang, W. Zhang et al., "Effect of different ozone treatments on the degradation of deoxynivalenol and flour quality in fusarium-contaminated wheat," CyTA Journal of Food, vol. 18, no. 1, pp. 776-784, 2020. 
[24] W. Zhang, L. Li, Z. Shu et al., "Properties of flour from pearled wheat kernels as affected by ozone treatment," Food Chemistry, vol. 341, Article ID 128203, 2021.

[25] V. B. Jayaram, S. Cuyvers, K. J. Verstrepen, J. A. Delcour, and C. M. Courtin, "Succinic acid in levels produced by yeast (Saccharomyces cerevisiae) during fermentation strongly impacts wheat bread dough properties," Food Chemistry, vol. 151, pp. 421-428, 2014.

[26] M. J. Lee, M. J. Kim, H. S. Kwak, S.-T. Lim, and S. S. Kim, "Effects of ozone treatment on physicochemical properties of Korean wheat flour," Food Science and Biotechnology, vol. 26, no. 2, pp. 435-440, 2017.

[27] H. P. S. Sandhu, F. A. Manthey, and S. Simsek, "Ozone gas affects physical and chemical properties of wheat (Triticum aestivum L.) starch," Carbohydrate Polymers, vol. 87, no. 2, pp. 1261-1268, 2012

[28] L. M. Seitz, "Volatile compounds in wheat cultivars from several locations in Kansas," Developments in Food Science, vol. 37, pp. 2183-2203, 1995.

[29] F. Husson, M. Thomas, S. Kermasha, and J.-M. Belin, "Effect of linoleic acid induction on the production of 1-octen-3-ol by the lipoxygenase and hydroperoxide lyase activities of Penicillium camemberti," Journal of Molecular Catalysis B: Enzymatic, vol. 19-20, pp. 363-369, 2002.

[30] Q. Zhang, Y. Ding, S. Gu, S. Zhu, X. Zhou, and Y. Ding, "Identification of changes in volatile compounds in dry-cured fish during storage using HS-GC-IMS," Food Research International, vol. 137, Article ID 109339, 2020.

[31] J.-S. Zhang, Z.-L. Zhang, M.-Z. Yan, X.-M. Lin, and Y.-T. Chen, "Gas chromatographic-ion mobility spectrometry combined with a multivariate analysis model exploring the characteristic changes of odor components during the processing of black sesame," Analytical Methods, vol. 12, no. 41, pp. 4987-4995, 2020. 